\title{
FRACTURE MECHANICS APPROACH TO ESTIMATE RAIL WEAR LIMITS
}

\author{
M.L. Lyons \\ D.Y. Jeong \\ J.E. Gordon \\ Volpe National Transportation Systems Center \\ US Department of Transportation \\ Cambridge, Massachusetts, USA
}

\section{ABSTRACT}

This paper describes a systematic methodology to estimate allowable limits for rail head wear in terms of vertical head-height loss, gage-face side wear, and/or the combination of the two. This methodology is based on the principles of engineering fracture mechanics.

The concept of applying the principles of engineering fracture mechanics to examine structural integrity was originally introduced by the U.S. Air Force, and is now embraced by the commercial aircraft industry. Aircraft structures are based on fracture mechanics (also referred to as damage tolerance) principles. Moreover, the approach in conducting rail integrity research sponsored by the Government is based on damage tolerance principles.

The fracture mechanics methodology to estimate rail head wear limits is based on various assumptions regarding operational and environmental factors. These factors include rail size, foundation modulus, temperature difference, train speed, and rail test interval (i.e. tonnage between rail tests).

This paper describes the methodology based on engineering fracture mechanics to estimate rail wear limits. In addition, results and sensitivity studies from applying the methodology are presented.

\section{INTRODUCTION}

Wear may be defined as mechanically-induced surface damage that results in the progressive removal of material. Wear is caused by repetitive relative motion of surfaces in contact. The repetitive relative motion may be tangential (or sliding), normal or perpendicular to the wearing surface (i.e., impact), rolling contact, or some combination. For example, wheels traveling over railroad rail can experience some degree of slip, which results in both sliding and rolling. Wheels traveling over a rail joint can create dynamic impact loads which may cause the rail to deform and wear.

Wear is not a basic material property, such as elastic modulus or yield strength. Rather, wear depends on the conditions of the material's use. In addition, repeated stressing or surfaces in contact can cause cracks to form and grow. Consequently, wear can affect structural integrity.

In the context of railroad rail, wear is not a defect in the same sense as a crack, which is a stress raiser and intensifies the local state of stress, but it is a cause for rail removal. Wear reduces the overall cross-sectional area of the rail, which increases the magnitude of bending and normal stresses in the rail, thereby, reducing the capacity of the rail to carry load. Moreover, the two primary life-limiting factors for rail replacement are excessive head wear and fatigue life.

Wear itself may be a direct threat to rail integrity, but excessive wear combined with the presence of a transverse defect also poses a direct threat. In this regard, a fracture mechanics approach to develop guidelines for allowable rail wear limits appears to be a reasonable starting point.

This paper describes an approach based on fracture mechanics principles to estimate limits for rail wear in terms of head height loss and gage-face side wear, shown on an idealized rail head in Figure 1. The approach relies on results from previous research conducted in support of the Federal Railroad Administration (FRA). Moreover, the engineering fracture mechanics approach to estimate rail head wear limits comprises two parts: defect growth by metal fatigue and fracture from overload. 


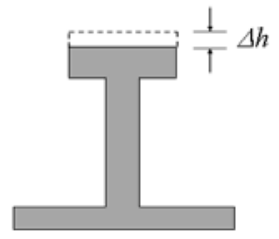

(a) Vertical Head-Height Loss

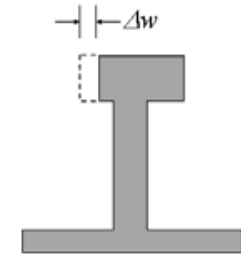

(b) Gage-Face Side Wear
Figure 1: Idealized Rail Head Wear Patterns

\section{FRACTURE MECHANICS METHODOLOGY}

Linear elastic fracture mechanics principles are applied to determine the amount of wear that would result in rail fracture when a rail containing a detail fracture (DF) of a given (assumed) size experiences a "once-per-train" wheel load. ${ }^{1}$ Wear is assumed to approach a limit when detail fractures can grow from a barely detectable size to a critical size in less than one-half an inspection period. The growth behavior of detail fractures in rails has been studied in previous research [1,2].

\section{Stress Intensity Factor for Detail Fractures}

For sizes less than 50 percent of the rail-head area (\%HA), the detail fracture is assumed to be an embedded elliptical flaw located in the vicinity of the upper gage corner of the rail head (Figure 2). The dimensions of the defect are characterized by the semi-major and semi-minor axes of the ellipse, $a$ and $b$, respectively. Examinations of rails containing detail fractures have revealed that the aspect ratio, $b / a$, is typically equal to 0.7 . The center of the detail fracture is characterized by its location relative to the unworn running surface, $z^{*}$, and the vertical mid-plane, $y$.

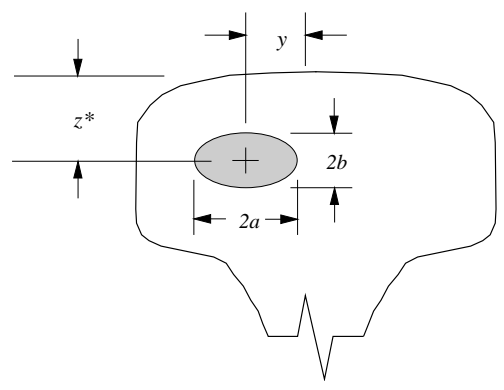

Figure 2: Schematic of a Detail Fracture in the Rail Head

A relationship between the location of the DF center and DF size in $136 \mathrm{RE}$ rail sections was derived empirically in the previous study [1]:

$y=1.1874-2.9523 \cdot\left(\frac{A}{A_{H}}\right)+3.4306 \cdot\left(\frac{A}{A_{H}}\right)^{2}$

\footnotetext{
1 Detail fractures are the most common transverse rail head defect found in continuous welded rail.
}

$$
z^{*}=0.6213+1.7580 \cdot\left(\frac{A}{A_{H}}\right)-1.7933 \cdot\left(\frac{A}{A_{H}}\right)^{2}
$$

where $A$ is the size of the detail fracture in terms of area $(A$ $=0.7 \pi \mathrm{a}^{2}$ ) and $A_{H}$ is the cross-sectional area of an unworn or new rail head. The parabolic trend characterized by these equations for $136 \mathrm{RE}$ rail was assumed to be constant for other rail sizes. In addition, the depth of the DF center below the rail running surface and inward from the gage face was assumed to be independent of rail size; i.e., varying only with the defect area ratio, $A / A_{H}$.

The stress intensity factor or " $K$ " formula for the embedded elliptical flaw shown schematically in Figure 2 has the following mathematical form:

$$
K_{I}=\frac{2}{\pi} \cdot M_{S}\left(\frac{b}{a}\right) \cdot M_{1}(a) \cdot \sigma_{\infty} \cdot \sqrt{\pi a}
$$

where $\sigma_{\infty}$ is the longitudinal tensile stress at the defect center due to rail bending and other effects, $a$ is the semi-major axis of the elliptical flaw, $M_{s}$ is a magnification factor to account for the elliptical flaw shape, and $M_{1}$ is a magnification factor to account for finite boundaries. The magnification factors for detail fractures were derived in Reference [1]. For instance, for an elliptical flaw aspect ratio of $b / a=0.7, M_{s}=0.984$. The finite-section magnification factor was modified from the original formulation to account for loss of rail-head area from wear, and is given by:

$$
\begin{aligned}
& M_{1}(a, X)=\sqrt{\frac{2}{\pi \cdot f(a, X)} \tan \left(\frac{\pi}{2} \cdot f(a, X)\right)} \times \\
& \left\{\frac{0.63+2.02 \cdot f(a, X)+0.37\left[1-\sin \left(\frac{\pi}{2} \cdot f(a, X)\right)\right]^{3}}{\cos \left(\frac{\pi}{2} \cdot f(a, X)\right)}\right\} \\
& f(a, X)=0.7 \pi a^{2} / A_{H}\left(1-\frac{X}{100}\right)
\end{aligned}
$$

where $X$ is a measure of wear in terms of percent rail-head area (\%HA). The aspect ratio of 0.7 for typical detail fractures has been included in equation (4).

The " $K$ " formula given in equation (3) applies to remote uniform tension only. A stress-gradient magnification factor must also be applied to the " $\mathrm{K}$ " formula if the rail head is subjected to a non-uniform stress field, which is the case when the rail is subjected to two-axis bending from vertical and lateral loads. The stress-gradient or non-uniform stress magnification factor depends on the ratio of lateral to vertical wheel load as well as defect size relative to the unworn rail head area. 


\section{Stress Analysis for Rails with Detail Fractures}

The magnitude of the stresses that drive the growth of detail fractures is assumed to be a linear superposition of residual, thermal, and bending stresses. Referring to equation (3), the longitudinal stress is calculated from

$\sigma_{\infty}=\sigma_{R}+\sigma_{T}+M_{G}(a) \cdot \sigma_{B}$

where $\sigma_{R}$ is the residual stress, $\sigma_{T}$ is the thermal stress, $M_{G}$ is the stress gradient or non-uniform stress magnification factor, and $\sigma_{B}$ is the bending stress.

Rail head wear reduces the section properties (i.e. cross sectional area and moments of inertia), which in turn increase the longitudinal stresses due to bending. Section properties for worn rail are approximated by assuming that the rail head cross section is idealized as a rectangle. Moreover, the equations to estimate section properties for worn rail are given in the Appendix.

Contact stress is not included in the present stress analysis because of the following reasons. Contact stresses are confined to a narrow region near the wheel/rail interface. Based on previous research [3], the axial component of Hertzian stress is calculated to be sufficiently low enough that it can be neglected at depths where detail fractures typically grow. In addition, contact stresses are compressive in nature. Moreover, it is assumed in the present crack-propagation analysis that compressive stresses do not contribute to crack growth.

A relationship between the magnitude of tensile residual stress in the rail head and the DF size has been developed on the basis of experimental data obtained from two separate tests $[1,4]$ conducted at the Facility for Accelerated Service Testing (FAST):

$\sigma_{R}= \begin{cases}30-2.125 \cdot\left(\frac{A}{A_{H}} \times 100\right) & \text { for } 0 \% H A \leq\left(\frac{A}{A_{H}} \times 100\right) \leq 10 \% H A \\ 10-0.125 \cdot\left(\frac{A}{A_{H}} \times 100\right) & \text { for }\left(\frac{A}{A_{H}} \times 100\right)>10 \% H A\end{cases}$

where $\left(A / A_{H} \times 100\right)$ represents the DF size in percent rail-head area (\%HA).

Thermal stresses for fully restrained CWR in tangent track can be calculated from

$\sigma_{T}=E \alpha \Delta T$

where $\alpha$ is the linear coefficient of thermal expansion, $E$ is the modulus of elasticity, and $\Delta T$ is the temperature difference between the in-service temperature and the neutral or stressfree temperature. In the present calculations, $\Delta T$ is an assumed variable.

Rail bending stresses comprise five components: (1) vertical bending, (2) lateral bending, (3) vertical head-on-web bending, (4) lateral head-on-web bending, and (5) warping. Moreover, these components are calculated based on the assumption that a rail behaves as a beam on a continuous elastic foundation $[5,6]$. As such, the maximum tensile stress in the rail head occurs at some distance away from the point of load application. Referring to Figure 3, the maximum bending moment occurs directly beneath the wheel load. The bending stress in the rail head for this maximum moment is compressive. The maximum tensile stress in the rail head occurs due to a phenomenon referred to as "reverse" bending. The figure also shows that the location of the maximum "reverse" moment for vertical bending relative to the wheel position is defined by

$x_{0}=\frac{\pi}{2 \lambda_{v}}$

$$
\lambda_{V}=\sqrt[4]{\frac{k_{V}}{4 E I_{y y}}}
$$

In equation (9), $k_{V}$ is the vertical foundation modulus, $E$ is the modulus of elasticity of rail steel, and $I_{y y}$ is the rail section moment of inertia for vertical bending.

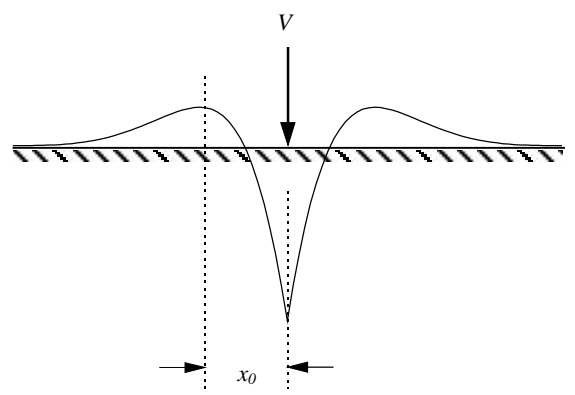

Figure 3: Bending Moment Distribution for a Single Wheel Load

Therefore, if only the vertical and lateral bending components are considered, the longitudinal stress in equation (5) for the fracture analysis may be calculated from

$\sigma_{B}=\frac{M_{V}\left(x_{0}\right) \cdot\left(h-h_{N}\right)}{I_{y y}}+\frac{M_{L}\left(x_{0}\right) \cdot w_{H}}{2 I_{z z}}$

where $h$ is the total rail height, $h_{N}$ is the distance from the bottom of the rail to the centroid of the rail, and $w_{H}$ is the width of the rail head. In equation (10), $h, h_{N}, w_{H}, I_{y y}$, and $I_{z z}$ are affected by changes in rail head wear (See Appendix). In addition, bending moments due to vertical and lateral wheel loads, $V$ and $L$ respectively, are calculated from

$$
\begin{aligned}
& M_{V}(x)=-\frac{V}{4 \lambda_{V}} e^{-\lambda_{V} x}\left(\cos \lambda_{V} x-\sin \lambda_{V} x\right) \\
& M_{L}(x)=-\frac{L}{4 \lambda_{L}} e^{-\lambda_{L} x}\left(\cos \lambda_{L} x-\sin \lambda_{L} x\right)
\end{aligned}
$$


where

$\lambda_{L}=\sqrt[4]{\frac{0.85 k_{V}}{4 E I_{z z}}}$

In equation (13), $I_{z z}$ is the rail section moment of inertia for lateral bending. In addition, the lateral foundation modulus is assumed to be $85 \%$ of the vertical foundation modulus. ${ }^{2}$

A more detailed description of the stress analysis used to calculate growth of detail fractures, which includes all components of the longitudinal stress, can be found in Reference [1].

\section{Wear Limit Estimation}

Rail-wear limits are estimated by combining results from two separate sets of calculations. In the first set of calculations, rail wear is determined as a function of critical DF size. In other words, equation (3) is set equal to the fracture toughness of rail steel for different critical DF sizes and different levels of rail wear. Results from this numerical procedure are shown schematically in Figure 4. An extreme temperature difference from the neutral or stress-free temperature of $50^{\circ} \mathrm{F}$ is nominally assumed. In addition, a dynamic magnification is applied to magnify the magnitude of a static wheel load during calculation of the stress intensity factor. Details of the dynamic wheel load calculation for this purpose (referred to as the $0.8-\sigma$ load level) are described in the next section of this paper.
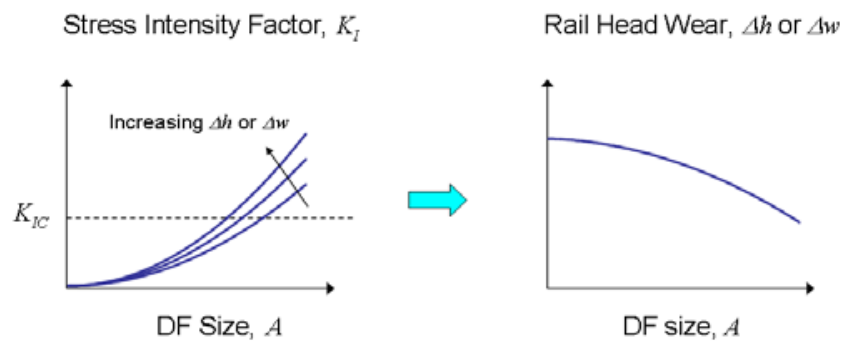

Figure 4: Schematic for Estimating Rail Wear as a Function of
Critical DF Size

When we consider only the results from this first set of calculations, the question is: what critical-size defect should be considered in estimating the rail-wear limit? To answer this question, we assume that rail wear becomes critical (i.e., reaches a limit) when detail fractures can grow from a barely detectable size (assumed to be $5 \% \mathrm{HA}$ ) to a critical size in less than one typical inspection interval. For this purpose, we assumed 20 MGT. Thus, a second set of calculations is performed to determine the DF size that will be reached after

\footnotetext{
${ }^{2}$ This assumption is based on limited data corresponding to well-maintained track [3]. The actual value is strongly sensitive to the degrading effects of missing spikes and/or ineffective ties.
}

20-MGT traffic accumulation for various levels of rail wear, assuming an initial DF size of $5 \% \mathrm{HA}$. In these DF-growth calculations, a moderate temperature differential of $15{ }^{\circ} \mathrm{F}$ is nominally assumed. Figure 5 shows a schematic of the results from this second set of calculations. Reference [1] describes propagation analyses of detail fractures which are used in the present calculations.

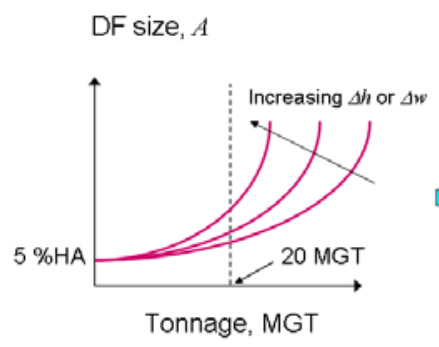

Rail Head Wear, $\Delta h$ or $\Delta w$

Figure 5: Schematic for Estimating Rail Wear as a Function of DF Size after 20 MGT from Initial DF Size of 5 \%HA

The results from the two sets of calculations described above can be combined, as shown in the schematic diagram in Figure 6 . The intersection of the two curves; one based on fracture toughness and the other based on DF-growth rate; defines the limit for rail wear.

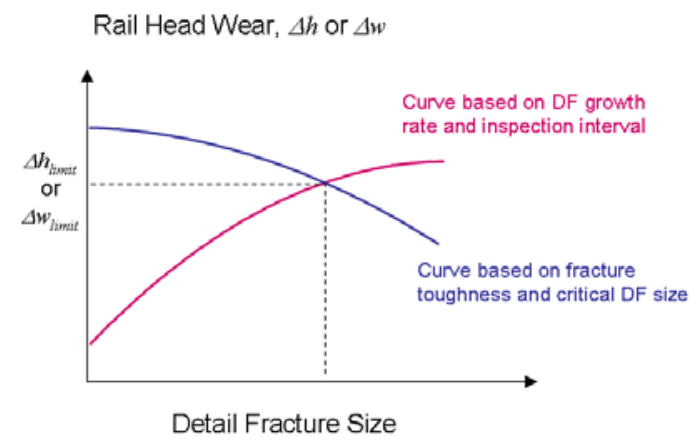

Figure 6: Estimate of Rail-Wear Limit Based on Fracture Mechanics Approach

\section{WORST-CASE LOAD ESTIMATION}

Car body and truck dynamic motions (pitch, bounce, and rocking) cause wheel loads to vary at frequencies up to $10 \mathrm{~Hz}$. For a given static wheel load, $V$, this dynamic load $V \pm V_{D}$ can be modeled as a Gaussian random process with probability density functions:

$$
p\left(V \pm V_{D}\right)=\frac{1}{c_{v} V \sqrt{2 \pi}} \exp \left[-\frac{\left( \pm V_{D}\right)^{2}}{2\left(c_{v} V\right)^{2}}\right]
$$

where the coefficient of variation, $c_{v}$, scales the root-meansquare dynamic increment in terms of the static load. In 
measurements of actual data, however, differences have been observed between dynamic load increments and decrements. The statistical variation of dynamic loads should then be modeled with two one-sided Gaussian distributions to account for these observed differences. ${ }^{3}$ A schematic of these distribution functions is shown in Figure 7. The coefficient of variation corresponding to the dynamic load increment, ${c_{v}}^{+}$, is applicable in determining the worst-case load.

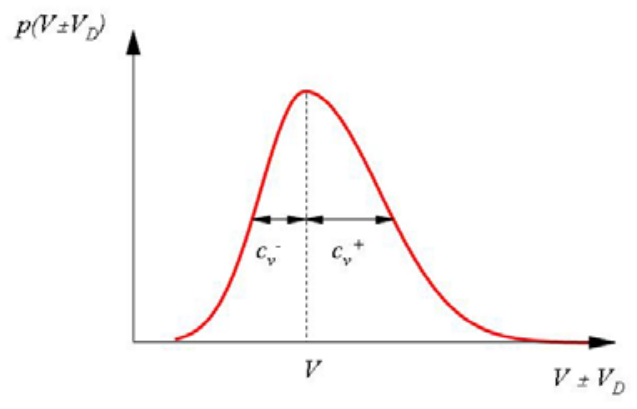

Figure 7: Schematic of Two-Sided Gaussian Probability Distribution Function

Physically, the worst-case load may be caused by a combination of several factors that include: (1) track irregularities and irregular track stiffness due to variable characteristics and settlement of the ballast; (2) discontinuities at welds, joints, and switches; (3) irregular rail-running surface (e.g., corrugated rail); (4) defects in vehicles such as wheel flats and wheel eccentricity; and (5) vehicle dynamics such as natural vibrations and hunting. Mathematically, the worst-case load is the average static wheel load multiplied by an extreme dynamic load magnification factor. The dynamic effect is assumed to increase with train speed, and its mathematical relationship to the coefficient of variation is discussed in the following text.

Procedures are described in Reference [1] to determine the coefficients of variation from load data given in the form of either exceedance curves or cumulative probability curves. Results from applying these procedures to freight-traffic load data from various sources are listed in Table 1 . Table 1 is an abstract, from Reference [1], of those results for which ${c_{v}}^{+}$ values can be related to loaded-freight train speeds.

In the present analysis, the "worst-case" load can be defined in terms of the number of standard deviations above the mean value. The coefficient of variation, $c_{v}$, is related to the standard deviation by the static wheel load, $V$, as given in the following expression:

$c_{v}=\frac{\sigma}{V}$

\footnotetext{
${ }^{3}$ In addition, separate distributions are usually required to match the dynamic behavior of lightly and heavily loaded cars. To simplify the present analysis, however, fully loaded cars are considered.
}

Table 1: Coefficients of Variation for Dynamic Vertical Load

\begin{tabular}{|c|c|c|c|c|}
\hline & Environment Description [Ref.] & $\begin{array}{c}\text { Average } \\
\text { Wheel } \\
\text { Load } \\
\text { (kips) }\end{array}$ & $\begin{array}{l}\text { Speed } \\
(\mathrm{mph})\end{array}$ & $\begin{array}{l}c_{v} \\
\text { for } \\
+V_{D}\end{array}$ \\
\hline 1 & FAST, concrete tie, 1977 [7]. & 30.5 & 40 to 45 & 0.26 \\
\hline 2 & $\begin{array}{l}\text { Loaded coal hopper car over } 1,900 \\
\text { miles on six midwestern and eastern } \\
\text { railroads [8]. }\end{array}$ & 30.0 & $\begin{array}{l}15 \text { to } 30 \\
30 \text { to } 45 \\
45 \text { to } 60\end{array}$ & $\begin{array}{l}0.20 \\
0.17 \\
0.22\end{array}$ \\
\hline 3 & $\begin{array}{l}\text { DOT-112A, 33,000-gal tank car over } \\
114 \text { miles of a Midwestern railroad } \\
\text { mainline [8]. }\end{array}$ & 30.0 & $\begin{array}{l}15 \text { to } 30 \\
30 \text { to } 45 \\
45 \text { to } 60\end{array}$ & $\begin{array}{l}0.17 \\
0.25 \\
0.60\end{array}$ \\
\hline 4 & $\begin{array}{l}\text { Hopper car loaded with crushed rock } \\
\text { over } 182 \text { miles on a western railroad } \\
\text { mainline [8]. }\end{array}$ & 30.0 & $\begin{array}{l}15 \text { to } 30 \\
30 \text { to } 45 \\
45 \text { to } 60 \\
>60\end{array}$ & $\begin{array}{l}0.08 \\
0.10 \\
0.11 \\
0.12\end{array}$ \\
\hline 5 & FAST, concrete tie, circa 1977 [9]. & 27.7 & 40 to 45 & 0.30 \\
\hline 6 & $\begin{array}{l}\text { Northeast Corridor, freight, concrete } \\
\text { tie, Edgewood, MD, } 1984 \text { [10]. }\end{array}$ & $\begin{array}{l}24.17 \\
24.32\end{array}$ & 45 to 70 & $\begin{array}{l}0.31 \\
0.33\end{array}$ \\
\hline
\end{tabular}

As indicated in Table 1, the coefficient of variation appears to vary with speed. This is consistent with the American Railway Engineering and Maintenance-of-Way Association (AREMA) formula for dynamic load factor [11]:

$D L F=1+\frac{33 v}{100 D}$

where $v$ is the train speed (in miles per hour) and $D$ is the wheel diameter (in inches).

For the purpose of load estimation, $c_{v}$ can be considered as comparable to the term $33 v / 100 D$ in the AREMA formula. Figure 8 compares this term (assuming $D=36$ inches) with the $c_{v}$ data from Table 1 . With only one exception, the formula term bounds the data in Table 1, and is therefore a reasonable representation of the service environment.

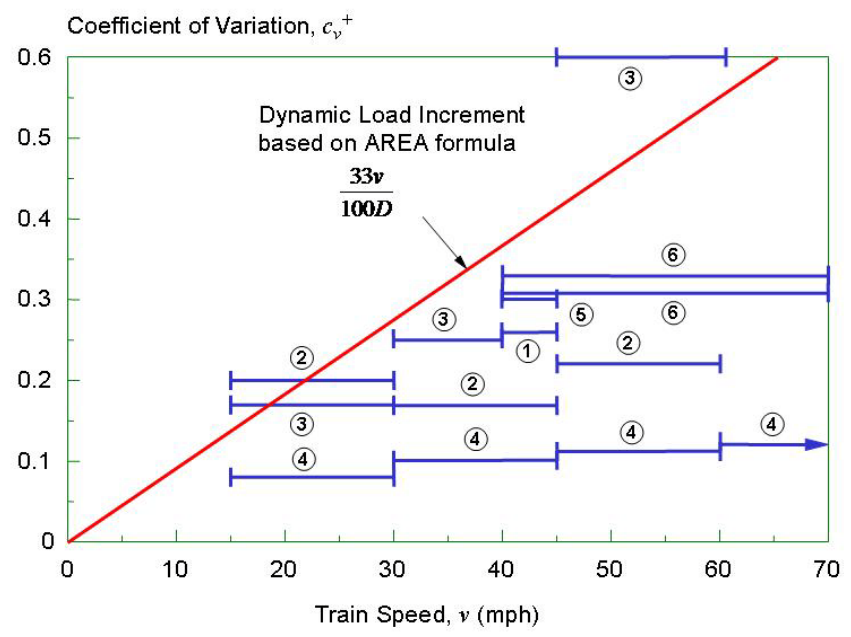

Figure 8: Speed Dependence on Coefficient of Variation and Dynamic Load Increment 
Figure 9, reproduced from Reference [1], shows the numbers of extreme-valued peak dynamic wheel loads measured in a field test on the Northeast corridor in the early 1980s [10]. Table 2 summarizes the results for freight trains, which were typically operated at $60 \mathrm{mph}$ through the instrumented site. Taking $v=60 \mathrm{mph}$ and assuming that the extreme loads came from loaded 100-ton cars (corresponding to a static load, $V$, equal to $33 \mathrm{kips}$, and a wheel diameter, $D$, equal to 36 inches), we may apply the previous analysis to estimate the standard deviation as $\sigma=c_{v}$ and $V=18.2$ kips. Thus, the range of 55 to 80 kips for extreme loads listed in Table 2 can be interpreted as roughly 1.2- $\sigma$ to 2.6- $\sigma$ events.

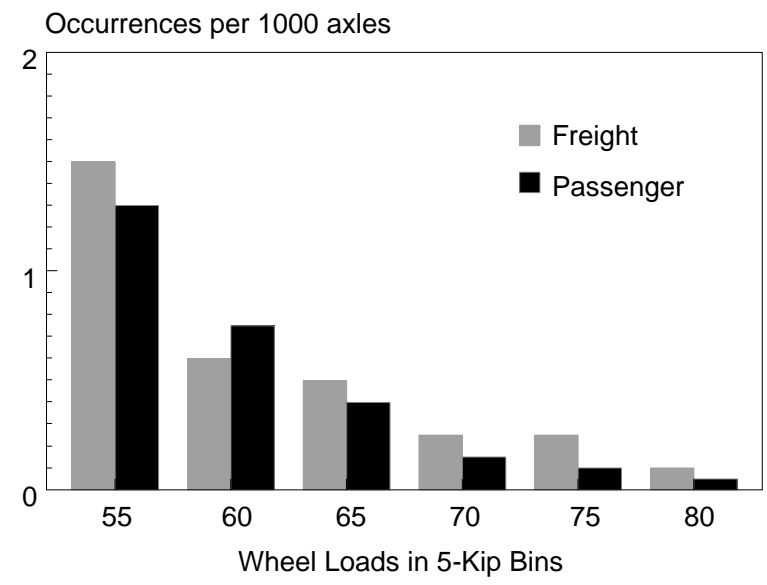

Figure 9: Histogram of Extreme Wheel Loads Measured on the Northeast Corridor

Table 2: Summary of Freight-Car Wheel-Load Histogram

\begin{tabular}{|c|c|}
\hline $\begin{array}{c}\text { Peak Load } \\
V_{\text {peak }} \text { (kips) }\end{array}$ & $\begin{array}{c}\text { Occurrences per 1000 } \\
\text { axles } \\
n\end{array}$ \\
\hline 55 & 1.50 \\
\hline 60 & 0.60 \\
\hline 66 & 0.50 \\
\hline 70 & 0.25 \\
\hline 75 & 0.25 \\
\hline 80 & 0.10 \\
\hline
\end{tabular}

Although the peak values in Table 2 occur infrequently, they cannot be assumed to bound the worst case because the loads were measured only for a limited time at a single site. Therefore, it is necessary to extrapolate from the available data in order to estimate worst-case loads for various operating speeds. For this purpose, the regression formula

$V_{\text {peak }}=\frac{2.4-\log _{10} n}{0.042}$ has been derived from a least-square-error analysis of the data listed in Table 2. Figure 10 compares equation (13) with the data points.

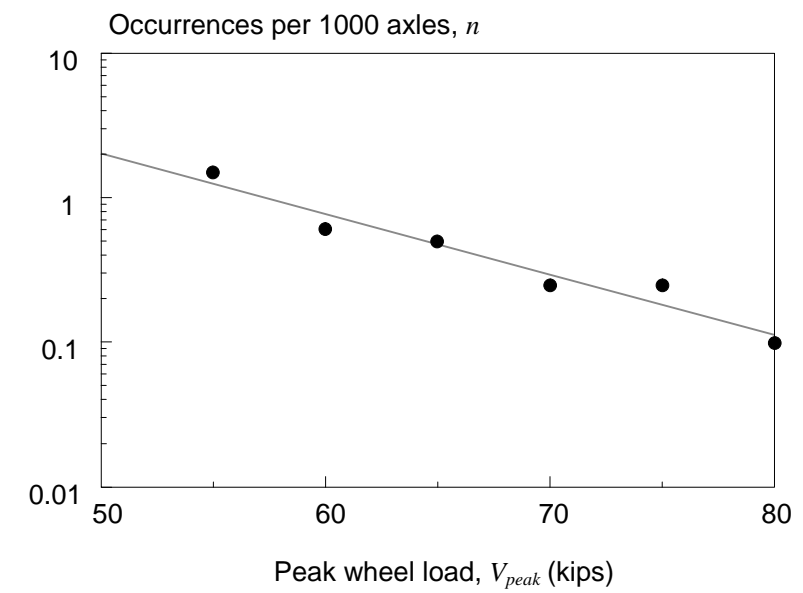

Figure 10: Regression for Occurrence Rate versus Peak Load

For randomly occurring events such as peak loads, the generally accepted definition of a worst-case event for the purpose of risk analysis is one expected to be exceeded no more often than once in $10^{5}$ to $10^{6}$ times. For example, when the Gaussian distribution is used to model a random process, the $5-\sigma$ level is sometimes used to define the worst case. The $5-\sigma$ level of a Gaussian process has an exceedance rate of $1.6 \times 10^{-6}$, which lies within the range mentioned above. There is no justification for applying the Gaussian model to extreme wheel loads, but it is reasonable to adopt the $1.6 \times 10^{-6}$ exceedance rate per axle passage as a worst-case criterion. Also, since there is no significant numerical difference between exceedance and occurrence rates at these extremes, we may take the corresponding occurrence rate as $n=1.6 \times 10^{-3}$ per thousand axles and apply equation (17) to estimate the worst-case load as:

$V_{\max }=\frac{2.4-\log _{10}\left(1.6 \times 10^{-3}\right)}{0.042} \cong 124 \mathrm{kips}$

The above worst-case load estimate applies to the Northeast Corridor field-test site, for which $\sigma=18.2$ kips was derived earlier as the standard deviation of the entire dynamic load range. Thus, the 5- $\sigma$ dynamic load increment above the static wheel load appears to be a reasonable criterion for estimating worst-case wheel loads at operating speeds and/or wheel diameters other than those associated with the test site. Table 3 summaries the worst-case loads estimated for the maximum operating speeds allowed on FRA Classes 2 through 5 track, assuming a 33-kip static load and a 36-inch wheel diameter. In the right-hand column are suggestions for typical and minimum rail sections representative of track construction 
for the corresponding class. In the wear-limit analyses, vertical foundation stiffness is assumed to vary with different track classifications. The assumed values for vertical foundation stiffness for each class track are also listed in Table 3.

The load level selected as a basis for wear-limit estimation depends on the mode of failure assumed. Since the present methodology is based on engineering fracture mechanics or damage tolerance, the assumed mode of failure is propagation of a fatigue crack to fracture. To realistically treat this case requires one to recognize that sparsely distributed cracks (typically, 0.25 to 2 per track mile) are not necessarily found where the most extreme or worst-case dynamic loads occur. A realistic extreme load basis for damage tolerance is the level expected once per train passage; i.e., about once per 400 axles assuming a 100-car freight train. The corresponding value of $n$ in equation (17) would be 2.5 per 1000 axles which gives a value of $V_{\max }$ equal to $47.7 \mathrm{kips}$, corresponding to a $0.8-\sigma$ load level (assuming a 33-kip static wheel load). Table 3 also lists values of worst-case loads based upon the 0.8- $\sigma$ load level which are subsequently applied in the damage-tolerance calculations for estimating rail wear limits.

Table 3: Representative Worst-Case Load Estimates with Corresponding Foundation Modulus

\begin{tabular}{|c|c|c|c|c|c|}
\hline $\begin{array}{l}\text { FRA } \\
\text { Track } \\
\text { Class } \\
\text { (a) }\end{array}$ & $\begin{array}{c}\text { Maximum } \\
\text {.Train } \\
\text { Speed } \\
v \text { (mph) } \\
\text { (b) }\end{array}$ & $\begin{array}{c}\text { Coefficien } \\
\text { tof } \\
\text { Variation } \\
C_{v}^{+} \\
\text {(c) }\end{array}$ & $\begin{array}{c}\text { Standard } \\
\text { Deviation } \\
\sigma \text { (kips) } \\
\text { (d) }\end{array}$ & $\begin{array}{l}\text { Worst- } \\
\text { Case } \\
\text { Load } \\
V_{\max } \\
\text { (kips) } \\
\text { (e) }\end{array}$ & $\begin{array}{c}\text { Vertical } \\
\text { Modulus } \\
k_{v} \text { (psi) } \\
\text { (f) }\end{array}$ \\
\hline 1 & 10 & 0.09 & 3.0 & $35 / 48$ & 1,000 \\
\hline 2 & 25 & 0.23 & 7.6 & $39 / 71$ & 1,000 \\
\hline 3 & 40 & 0.37 & 12.1 & $43 / 94$ & 2,000 \\
\hline 4 & 60 & 0.55 & 18.2 & $48 / 124$ & 2,000 \\
\hline 5 & 80 & 0.73 & 24.1 & $52 / 154$ & 5,000 \\
\hline
\end{tabular}

NOTES:

(a) FRA Track Safety Standards do not require rail testing for internal rail defects in Class 1 and 2 Track.

(b) Maximum train speeds are based on FRA Track Safety Standard for freight traffic, specified in the Code of Federal Regulations (49 CFR § 213.9).

(c) Coefficient of variation calculated from: $c_{v}=33 v / 100 D$ where $D=36$ inches.

(d) Standard deviation calculated from: $\sigma=c_{V} V$ where $V=33$ kips.

(e) Worst-case loads are calculated from: $V_{\max }=V+0.8 \sigma$ and $V_{\max }=V+5.0 \sigma$. The loads corresponding to $0.8-\sigma$ above the static value were applied in the fracture mechanics methodology presented in this paper.

(f) Reference [13] lists values of 2,000 to 2,500 psi for good conventional track, and values of 7,000 to 8,000 psi for concrete-tie track.

\section{RESULTS}

Results from applying the methodology for 115RE rail are shown in Figure 11 which displays various combinations of vertical head and gage face wear for different FRA track classes. FRA Track Class 5, with the highest speed, has the lowest rail head wear limits. In other words, rail wear limits become more restrictive for higher track class since train derailments are likely to cause more harm on a higher class track than on lower classes because of higher speeds and the type of traffic.

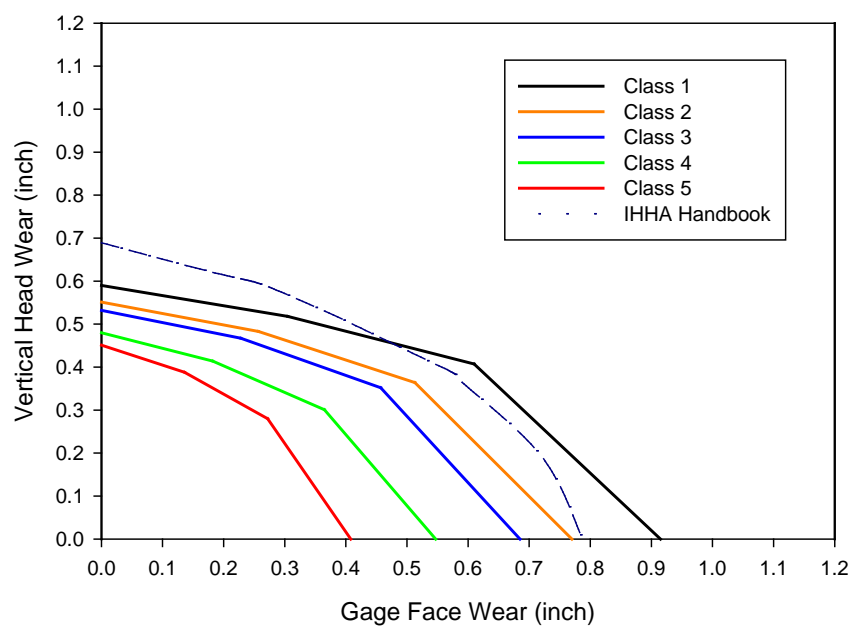

Figure 11: Combined Vertical Head and Gage Face Wear Limits for 115RE

Similarly, Figure 12 shows rail head wear limits for 136RE estimated from the present methodology. The limits for the heavier rail section tend to be greater than those shown previously in Figure 11 for the lighter rail section.

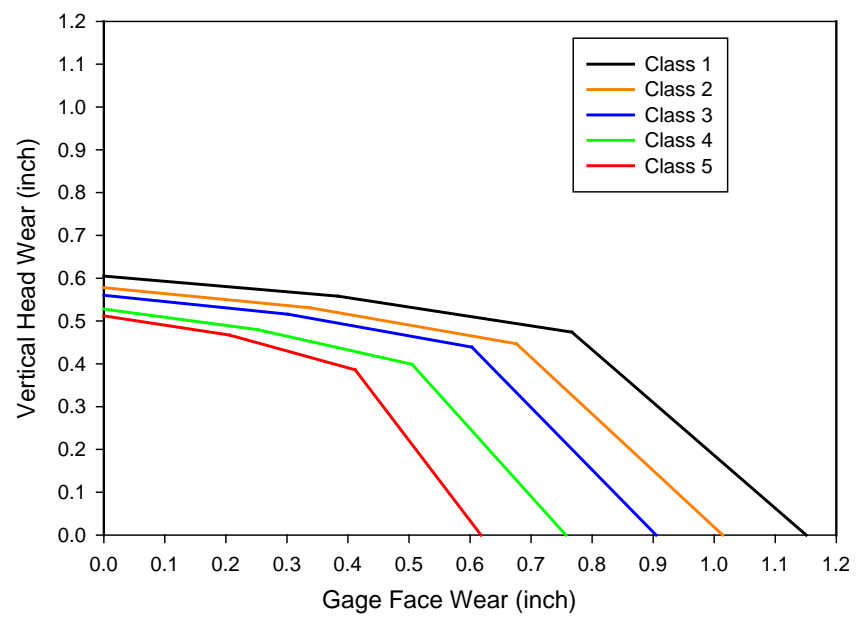

Figure 12: Combined Vertical Head and Gage Face Wear Limits for 136RE

\section{SENSITIVITY STUDIES}

The relative effect of the various input factors and values assumed in the fracture mechanics methodology are examined through a sensitivity analysis. Baseline values are established for the different factors, and varied one at a time while holding 
other factors equal to their baseline values to calculate the difference in estimated vertical head and gage face wear separately. Table 4 lists the different factors that are included in the methodology, the assumed baseline values, and variations from the baseline values for each factor.

Table 4: Factors and Assumed Values

\begin{tabular}{|l|c|c|}
\hline \multicolumn{1}{|c|}{ Factor } & Baseline Value & $\begin{array}{c}\text { Range of } \\
\text { Values }\end{array}$ \\
\hline Average Static Load & $16.5 \mathrm{kips}$ & 10 to 33 \\
\hline Extreme $\Delta T$ & $50^{\circ} \mathrm{F}$ & 30 to 70 \\
\hline Fracture Toughness & $35 \mathrm{ksi}-\mathrm{in}^{1 / 2}$ & 25 to 45 \\
\hline Inspection Interval & $20 \mathrm{MGT}$ & 10 to 30 \\
\hline Maximum Static Load & $34.75 \mathrm{kips}$ & 29.75 to 39.75 \\
\hline Moderate $\Delta T$ & $15^{\circ} \mathrm{F}$ & 5 to 25 \\
\hline Rail Size & 132 & 112 to 141 \\
\hline Train Speed & $40 \mathrm{mph}$ & 10 to 80 \\
\hline Vertical Modulus & $2,000 \mathrm{psi}$ & 1,000 to 5,000 \\
\hline
\end{tabular}

The relative effect of the different factors on the estimated vertical head and gage face wear limits is shown in Figure 13 and 14, respectively. The input factors are ranked by the greatest effect on rail wear. For example, the three most significant factors affecting vertical head-height loss are rail size, average static load, and train speed, while the average static load, inspection interval (i.e. rail test frequency), and train speed have the greatest effect on gage-face side wear. Conversely, maximum static load, vertical modulus, and extreme temperature differential are the three factors with relatively weak effects on the estimated vertical head and gage face wear limits.

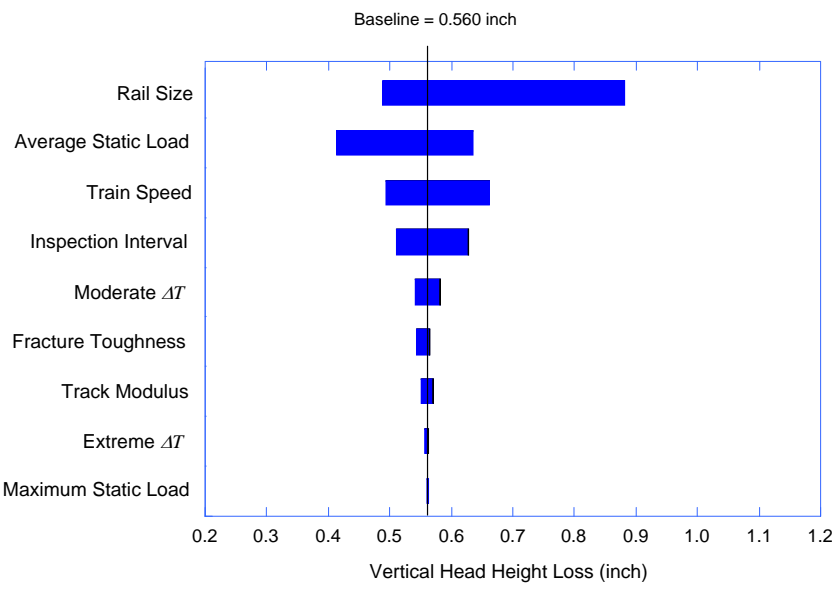

Figure 13: Relative Effect of Different Factors on Vertical Wear

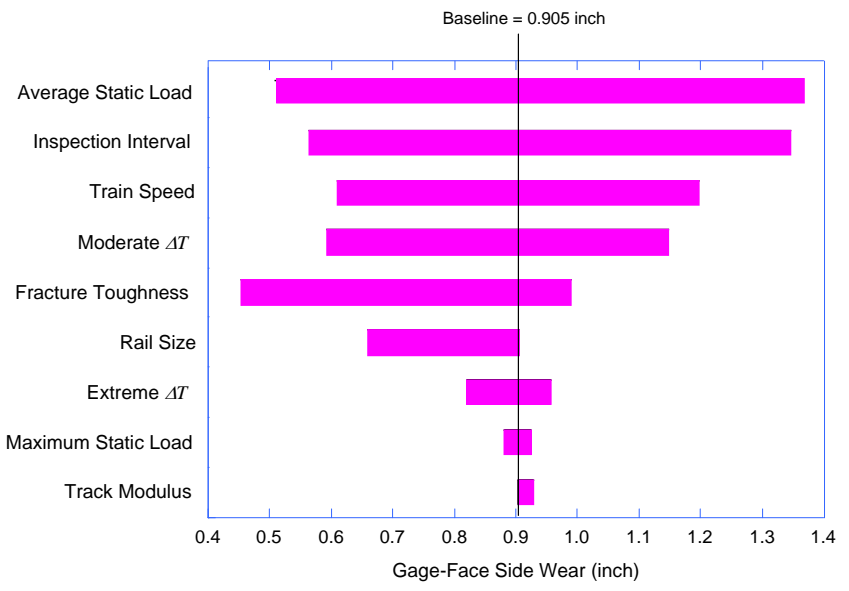

Figure 14: Relative Effect of Different Factors on Side Wear

\section{DISCUSSION}

Combined vertical head and gage face wear limits were presented for 115RE and 136RE rail sections on different FRA track classes. Estimates for rail wear limits tend to decrease as track class (i.e. train speed and track support conditions) increases. Figure 11 also shows the maximum wear limits for 115RE which are presented in Reference [14] using a different methodology. However, the rail limits described in Reference [14] do not specify the type of traffic or any other factor except rail size.

Results from the sensitivity analysis indicated that the same change in value of the different factors has a greater effect on side wear than vertical wear. That is, the length of the bars in Figure 14 is longer than those in Figure 13 for the same change in a given factor. An important difference in the two cases is an increase in applied lateral load. The lateral-tovertical $(L / V)$ ratio is assumed to be 0.05 in the calculation of vertical wear, and 0.4 for side wear. The corresponding increase in lateral wheel load increases the compressive bending stress in the vicinity where detail fractures grow, which amplifies the contribution of the tensile thermal stress due to temperature differential.

In previous research, another method to estimate rail wear limits was developed based on plastic collapse [15]. This alternative methodology, however, does not account for rail inspection interval (since defect growth is not considered) nor does it account for temperature differential. Rail head limits based on the fracture mechanics approach tend to be more conservative (i.e. restrictive) than those based on plastic collapse or permanent bending.

\section{CONCLUDING REMARKS}

This paper describes a methodology to estimate limits for vertical head and gage-face rail wear based on engineering fracture mechanics. Results are presented in terms of combined vertical head-height loss and gage-face side wear for different rail sections and FRA track class. In the present 
work, FRA track class is characterized by a combination of maximum train speed for freight traffic and foundation modulus. Sensitivity studies indicate that static load and train speed have the greatest effect on rail wear for both head-height loss and gage-face side wear. Temperature differential was found to have a significant effect on gage-face side wear.

\section{ACKNOWLEDGMENTS}

The work reported in this paper was carried out under the Rail Integrity Project in the Track Safety Research Program sponsored by the Office of Research and Development, Federal Railroad Administration, U.S. Department of Transportation, under the direction of Mr. Gary Carr, Chief of the Track Research Division. Mr. Ali Tajaddini is the Project Manager for the research related to rail integrity.

\section{REFERENCES}

[1] Orringer O, Tang YH, Gordon JE, Jeong DY, Morris JM, Perlman AB. “Crack Propagation Life of Detail Fractures in Rails,” Volpe Center Final Report DOT/FRA/ORD88/13, October 1988.

[2] Jeong DY, Tang YH, Orringer O. "Damage tolerance analysis of detail fractures in rail," Theoretical and Applied Fracture Mechanics 28 (1997) 109-115.

[3] Orringer O, Morris JM, Jeong DY. "Detail Fracture Growth in Rails: Test Results,” Theoretical and Applied Fracture Mechanics (1986) 63-95.

[4] Clayton P, Tang YH. "Detail fracture growth in curved track at the Facility for Accelerated Service Testing," Residual Stresses in Rails, Vol. 1. Kluwer Academic Publishers, The Netherlands (1992) 37-56.

[5] Hetenyi H. Beams on Elastic Foundation. University of Michigan Press, Ann Arbor, MI (1983).

[6] Timoshenko S, Langer BF. "Stresses in Railroad Track," ASME Transactions 54 (1932) 277-293.

[7] Ahlbeck DR, Johnson MR, Harrison HD, Tuten JM. "Measurements of Wheel/Rail Loads on Class 5 Track," Final Report, DOT/FRA/ORD-80/19, 1980.

[8] Johnson MR. "Summarization and Comparison of Freight Car Truck Load Data,” ASME Transactions, Journal of Engineering for Industry 100 (1978) 60-66.

[9] Zarembski AM. "Effect of Rail Section and Traffic on Rail Fatigue Life," American Railway Engineering Association Bulletin 673 (1979) 514-527.

[10] Tuten JM, Harrison HD. "Design, Validation, and Application of a Monitoring Device for Measuring Dynamic Wheel/Rail Loads," Proceedings of the ASME Winter Annual Meeting, Paper No. 84-WA/RT-10 (1984).

[11] AREMA Manual for Railway Engineering, Vol.1, Track, American Railway Engineering and Maintenance-of-Way Association (1999).

[12] Everett RA, Bartlett FD, Elber W. "Probabilistic Fatigue Methodology for Safe Retirement Lives," Journal of the American Helicopter Society (1992) 41-53.
[13] Hay WW. Railroad Engineering, $2^{\text {nd }}$ Edition. John Wiley \& Sons, Inc. New York, NY (1982).

[14] Guidelines to Best Practices for Heavy Haul Railway Operations: Wheel and Rail Interface Issues, International Heavy Haul Association, Virginia Beach, VA (2001).

[15] Jeong DY, Tang YH, Orringer O. "Estimation of Rail Wear Limits Based on Rail Strength Investigations," Volpe Center Final Report DOT/FRA/ORD-98/07, December 1998.

\section{APPENDIX - APPROXIMATION OF WORN RAIL SECTION PROPERTIES}

This appendix presents equations to estimate section properties used in the stress analysis of worn rails based upon the assumption that the actual rail cross section may be idealized as three rectangular sections representing the head, web, and base of the rail. Equivalence between the actual and idealized rails is achieved by matching section properties between the actual and idealized cross sections. In particular, the second area moments of inertia for the rail head about the vertical and horizontal axes through the centroids for the actual $I_{y y H}$ and $I_{z z H}$ and idealized rail heads are related by:

$$
I_{y y H}=\frac{1}{12} h_{e q}^{3} w_{e q} \quad I_{z z H}=\frac{1}{12} h_{e q} w_{e q}^{3}
$$

where $h_{e q}$ and $w_{e q}$ are the equivalent rail head height and width. After some algebraic manipulations, expressions for the equivalent rail-head height and width can be found:

$$
h_{e q}=\sqrt[8]{144 \frac{I_{y y H}^{3}}{I_{z z H}}} \quad w_{e q}=\sqrt[8]{144 \frac{I_{z z H}^{3}}{I_{y y H}}} .
$$

Table A1 lists the equivalent rail-head heights and widths for four different rail sections, as calculated from equations (A.2). The table also lists the rail-head cross-sectional area approximated by the product of these equivalent dimensions, and the percent difference between the approximate area and the actual unworn rail-head area, $A_{H}$.

Table A1: Equivalent Head Height and Head Width for Different Rail Sections

\begin{tabular}{|l|c|c|c|c|}
\hline & $100 \mathrm{RE}$ & $115 \mathrm{RE}$ & $132 \mathrm{RE}$ & $136 \mathrm{RE}$ \\
\hline$h_{e q}$ & 1.49 & 1.50 & 1.53 & 1.72 \\
\hline$w_{e q}$ & 2.57 & 2.57 & 2.82 & 2.77 \\
\hline$h_{e q} \times w_{e q}$ & 3.84 & 3.87 & 4.30 & 4.75 \\
\hline$A_{H}$ & 3.80 & 3.91 & 4.42 & 4.86 \\
\hline$\%$ diff & $+1.1 \%$ & $-1.4 \%$ & $-2.6 \%$ & $-2.2 \%$ \\
\hline
\end{tabular}




\section{Head-Height Loss}

The loss of rail-head height and the equivalent rail-head height are related by

$$
\Delta h=\left(\frac{X}{100}\right) h_{e q}
$$

where $X$ is the percent of worn rail-head area. The second area moment of inertia for vertical bending for a worn rail is calculated from

$$
\begin{aligned}
& I_{y y}(X)=I_{Y^{\prime} Y^{\prime}}+A_{R}\left[h_{N}(0)-h_{N}(X)\right]^{2}-\frac{1}{12} \Delta h^{3} w_{e q} \cdots \\
& -\Delta h \underset{e q}{ } \psi\left[h-\frac{1}{2} \Delta h-h_{N}(X)\right]^{2}
\end{aligned}
$$

In this notation, $I_{Y^{\prime} Y^{\prime}}$ is the vertical bending inertia of the new or unworn rail, $h_{N}(0)$ refers to the distance from the bottom of the rail to the centroid of the new or unworn rail, and $h_{N}(X)$ is the distance from the bottom of the rail to the centroid of the worn rail, which is calculated from

$$
h_{N}(X)=\frac{A_{R} h_{N}(0)-A_{H} h_{H}(0)+\left(1-\frac{X}{100}\right) A_{H} h_{H}(X)}{A_{B}+A_{W}+\left(1-\frac{X}{100}\right) A_{H}}
$$

where $A_{R}$ is the cross-sectional area of the unworn rail. In addition, $A_{W}$ and $A_{B}$ are the areas of the web and base. The distance from the bottom of the rail to the centroid for the rail head only in a worn rail is calculated from

$h_{H}(X)=h-\frac{1}{2} \Delta h$.

where $h$ is the total height of the unworn rail.

\section{Gage-Face Side Wear}

The amount of gage-face side wear is related to the equivalent head width by

$$
\Delta w=\left(\frac{X}{100}\right) w_{e q} .
$$

The second area moments of inertia for vertical and lateral bending of a worn rail, in this case, are calculated, respectively, from

$$
\begin{aligned}
& I_{y y}(X)=I_{Y^{\prime} Y^{\prime}}+A_{R}\left[h_{N}(0)-h_{N}(X)\right]^{2}-\frac{1}{12} h_{e q}^{3} \Delta w_{e q} \ldots \\
& -h_{e q} \Delta w\left[h-\frac{1}{2} h_{e q}-h_{N}(X)\right]^{2} \\
& I_{z z}(X)=I_{Z^{\prime} Z^{\prime}}+A_{R} y_{N}(X)^{2}-\frac{1}{12} h_{e q} \Delta w^{3} \ldots \\
& -h_{e q} \Delta w\left[\frac{1}{2}\left(w_{e q}-\Delta w\right)+y_{N}(X)\right]^{2}
\end{aligned}
$$

A consequence of gage-face side wear is that the rail cross section is asymmetric with respect to the mid-plane centerline of the rail. Further, the coordinates of the centroid for the entire rail and for the rail head only are not located on the midplane centerline, as they are for a new or unworn rail (Figure A.1).

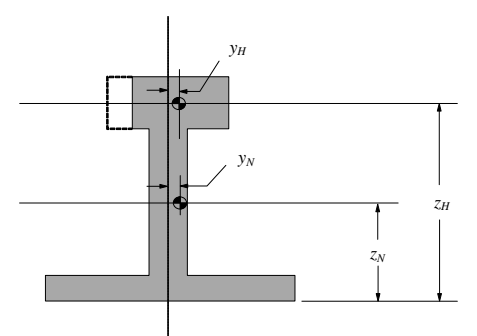

Figure A.1: Location of Centroids in Rail with Gage-Face Wear

The location of the centroid for the entire worn rail is defined by

$$
y_{N}(X)=\frac{\left(1-\frac{X}{100}\right) A_{H} y_{H}(X)}{A_{B}+A_{W}+\left(1-\frac{X}{100}\right) A_{H}}
$$

$$
h_{N}(X)=\frac{A_{R} h_{N}(0)-A_{H} h_{H}(0)\left(\frac{X}{100}\right)}{A_{B}+A_{W}+\left(1-\frac{X}{100}\right) A_{H}} .
$$

The vertical location for the centroid of the worn rail head only is assumed to remain unchanged from that of the new or unworn rail head. The horizontal location of the centroid for the worn rail head only is calculated by

$$
y_{H}(X)=\frac{1}{2} \Delta w
$$

